Nota del editor: El presente testimonio histórico del ex presidente de Bolivia Carlos Mesa Gisbert, recogido en una entrevista de dos académicos chilenos, no había sido publicado hasta la fecha, no obstante revestir un notable interés. La Revista Tribuna Internacional ha decidido darlo a conocer en su texto completo, sin perjuicio de observar que diversas afirmaciones que aquí se hacen representan una precisión subjetiva del destacado político boliviano, que no solo son discutibles sino que objetivamente rebatibles. La Revista Tribuna Internacional no las comparte y deja constancia de sus discrepancias. En forma precisa indica que Bolivia nunca tuvo "cualidad marítima" que fuese efectiva, útil y soberna, y que estuviese vinculada e integrada en su nación. Cobija o Puerto La Mar no funcionó como tal, y Antofagasta no fue creada por Bolivia ni poblada por sus nacionales. Fue un puerto establecido y poblado por chilenos $(93 \%$ de la población en 1879) y por inmigrantes europeos y asiáticos. El puerto utilizado por Bolivia, al igual que por la Audiencia de Charcas durante la Colonia, siempre fue Arica; y la historia revela las múltiples oportunidades en que desde su creación en 1825 solicitó al Perú la cesión de ese puerto, lo que fue rechazado permanentemente por ese país. Debe por lo mismo señalarse que la trilateralidad que sostiene Carlos Mesa, involucra un punto de vista que no cuenta con la aceptación oficial de Chile ni tampoco del Perú.

\title{
Mi Caída: Testimonio histórico del ex presidente de Bolivia Carlos Mesa Gisbert sobre su "presidencia sitiada" (2003/2005) ${ }^{1}$
}

\author{
My Fall: Historic Testimony from the former President of Bolivia Carlos Mesa Gisbert about \\ his "Surrounded Presidency" (2003/2005)
}

\author{
Juan E. Mendoza Pinto \\ jemendoza@udec.cl \\ Doctor en Estudios Americanos, Profesor Asociado, Departamento de Ciencias Históricas y Sociales \\ de la Universidad de Concepción.
}

\section{Eduardo Téllez Lúgaro}

edotellez@gmail.com

Doctor en Historia, docente e investigador del Centro de Estudios Históricos de la Universidad Bernardo O'Higgins.

\footnotetext{
${ }^{1}$ Texto recibido el 06.08.2016 y aceptado el 03.10.2016.
} 
Resumen: Presentamos un documento inédito sobre los conmovedores acontecimientos vividos por el Estado y la sociedad boliviana en la difícil coyuntura 2003/2005, asociada a la presidencia de Carlos Mesa G., que nos deja aquí una testificación directa, del más alto nivel, sobre ese trance histórico, de indudable valor para la historia contemporánea de América Latina.

Palabras clave: Gas - Gonzalo Sánchez de Losada - Evo Morales - Mar - Derechos Humanos - Conspiración.

Summary: We present an unpublished document on the poignant events experienced by the State and the Bolivian society in the difficult situation 2003/2005, associated with the presidency of Carlos Mesa G., leaving us here a direct witness, the highest level on this trance historical, of great value to the contemporary history of Latin America.

Keywords: Gas - Gonzalo Sánchez de Lozada - Evo Morales - Sea - Human Rights - Conspiracy.

\section{Presentación}

Con afabilidad, don de gentes y pasión, el historiador Carlos Mesa Gisbert, concedió este extenso relato sobre las vicisitudes de su oscilante gobierno -incluido un valioso recuento de las relaciones con Chile durante la presidencia de Ricardo Lagos- al Dr. Juan Eduardo Mendoza, en La Paz, Bolivia, en 28 de septiembre de 2009, bajo la forma de entrevista, a ratos convertida en grato e irónico diálogo. A posteriori, el texto fue readaptado, junto al Dr. Eduardo Téllez, al formato en cual se publica aquí. Dicha opción permite al lector seguir con fluidez la hechizante narración de Mesa Gisbert, cuando era adversario enconado del Presidente Evo Morales, y todavía parecía impensable verlo transfigurado en procurador principal de la causa marítima boliviana, por delegación de esa administración.

Sólo para dar orientación a quien hace la lectura hemos introducido una gama restringida de subtítulos, a fin de situarlo en la temática abordada en el segmento. Excepto paréntesis y otros guiños permitidos por la ortografía castellana ${ }^{2}$, unas pocas e imprescindibles notas y una mínima expurgación de palabras mal ajustadas -debe recordarse siempre que, a la postre, fue ésta una conversación empática en que el coloquialismo cobró su precio- el testimonio rendido por Carlos Mesa se edita prácticamente intacto.

Su relevancia quedará evidenciada desde las líneas primeras.

2 Hemos hecho amplio empleo del paréntesis en la textualidad del documento. Tratándose de corchetes rectos debe asumirse que son aclaraciones puntuales introducidas por los recopiladores con el objeto de redondear ideas y referencias entregadas por Carlos Mesa o mejorar la comprensión del contexto. Los corchetes curvados indican suertes de introspecciones o inflexiones más intimistas introducidas por el narrador mismo. 


\section{El contexto histórico de la crisis altiplánica de 2003}

"Lo primero que hay que comprender es que en Bolivia existen dos fuerzas, una exógena, la española y otra endógena, la indígena ${ }^{3}$... que van a presionar sobre el Estado, representado por una estructura, por un sistema de partidos, por una elite que gobierna. Esos dos brazos son muy importantes. En este momento [2003], Santa Cruz no juega un rol fundamental. No es que no lo tenga desde el punto de vista económico. Y no lo creo; por una razón muy simple: porque el Estado boliviano, en el periodo 1982/2003, contra todo el discurso cruceño (el cual es una de las típicas frases hechas)... siempre estuvo incorporado al poder. En mi libro Presidencia Sitiada, hay una lista de todos los ministros de Estado cruceños que controlaban los ministerios más importantes del país en el periodo democrático 1982/2003. Por eso Santa Cruz, en ese momento -el de la guerra del gas, septiembre/octubre de 2003- no juega un papel de contrapoder. Es decir, de ser el núcleo que defendiera los intereses de las elites que estaban siendo atacadas aquí, en la sede de gobierno. Entonces, creo que las dos cosas fundamentales son las mencionadas. La radicalidad indígena de Quispe y el movimiento cocalero de Evo Morales, que fue instalado en el sistema partidario a partir del MAS, y el segundo lugar que ocupa en la elección que ganamos con Gonzalo Sánchez de Lozada, el año 2002.

...En una dimensión radicalmente distinta a la que viene después, en 2005, el planteamiento que hace Santa Cruz es su preocupación [sobre] la situación nacional. Porque ve que el país está afrontando una crisis grave, e incluso se anima a hacer una propuesta política: que pudiera integrar un proceso y un modelo de desarrollo, en el sentido más tradicional, pero sin lo importante del modelo exportador, del modelo productivo. Todo lo que la elite agroindustrial cruceña ha defendido a lo largo del tiempo, lo incorpora o plantea como necesario de incorporar; pero no plantea la autonomía. No plantea la autonomía. También por una razón muy simple: porque los dos presidentes más emblemáticos de lo que podría ser la consolidación del poder cruceño, por una parte Hugo Banzer Suárez, por la otra Gonzalo Sánchez de Lozada, por diferentes motivos, son enemigos de la autonomía. Banzer, porque es un Presidente que viene del militarismo, y el militarismo tiene una visión unitarista del Estado; y a pesar de ser cruceño tiene miedo de que el tema de las autonomías se le convierta en un problema, y no lo toca. Por otra parte, Sánchez de Lozada, por convicción, cree que las autonomías son el punto de partida de la disgregación política del gobierno; y por lo tanto él es militantemente contrario a las autonomías, y así se lo expresa a los cruceños. Pero como a la vez, Sánchez de Lozada representa en su propio núcleo de poder a los sectores de poder más importantes de Santa Cruz, Santa Cruz no se enfrenta con Sánchez de Lozada. Recuerdo que en septiembre de 2003, cuando el ex Presidente Sánchez de Lozada, pronuncia un discurso

3 Salvo expresa indicación nuestra, deberá asumirse que las negrillas representan énfasis dados por el entrevistado durante su discurso. 
donde alababa la otra Bolivia, para referirse al oriente... ahí quedo como en medio de esa imagen, de las dos caras de Bolivia: una que produce y otra que protesta".

\section{Las dos Bolivia, la Guerra del Gas, los 200 muertos de Sánchez de Lozada y el derrumbe del Gobierno de Mesa}

“...Un proceso que viene después -viene a partir de mi presidencia-... plantea una serie de, digamos, elementos nuevos, [los] que se incorporan en la agenda política [y] que desencadenan un nuevo proceso histórico.

Hay aquí dos consideraciones. Yo tengo que enfrentar dos problemas fundamentales en el momento en que llego a la presidencia referida [SIC: léase referidos] a los derechos humanos. Primer problema: un problema ético, [que]... suscita una polémica o algunas dudas en torno a si yo me estaba separando del Presidente Sánchez de Lozada por oportunismo o porque, en efecto creía que lo que estaba haciendo (desde un punto de vista de los muertos que ya teníamos, cuando... decido separarme) era una cuestión de convicción. Mi primera respuesta clara es que, en efecto, era una cuestión de convicción. Yo no podía acompañar a un gobierno, por muy buenas razones que tuviera (y las tenía), que estaba dispuesto a un costo $\mathrm{X}$ de vidas humanas a cambio de la preservación de la democracia.

Hubieron [SIC: léase hubo] diferentes puntos de vista. Pasa que en el gobierno del Presidente Sánchez de Lozada habían fusilados. Los gremios estaban cerca de esa cifra [200 muertos en las refriegas]. Los bandos estaban en contra del mismo socialismo; yo no representaba una posición personal, representaba una posición de una parte del gabinete, que, sin embargo, a diferencia mía, eran militantes del partido; y eso los tenía atrapados en la imposibilidad de una renuncia, que hubiera sido considerada como una cobardía en un momento tan complicado. Yo siempre fui un independiente, y eso me permitió una acción; pero puedo decir que había por lo menos tres o cuatro ministros de Estado, que si no hubieran sido militantes del partido del Presidente -y que le expresaron su lealtad-se hubieran retirado por que estaban en contra.

Esta primera consideración planteó la necesidad que expresara ésta convicción ética de manera inequívoca. Y un día antes de ser Presidente, cuando todavía no se sabía que yo lo iba a ser (Presidente)... dije: me han preguntado si estoy dispuesto a matar (porque había tenido conversaciones con periodistas, conversaciones internas, y [esta] era una forma de expresarme al país), y mi respuesta es no. No estoy dispuesto a matar, ni ahora ni mañana ni nunca. Ese fue el centro de mi discurso a la nación. Ese fue un elemento positivo y negativo, paradójico. Positivo, porque me diferenció claramente en los valores éticos que yo estaba planteándole a Bolivia. Negativo, porque me acordonaron, porque cuando yo tuve que tomar decisiones de estado en función de mi obligación constitucional, tuve que enfrentar el dilema 
del cumplimiento de mi palabra o del peligro - para garantizar la estabilidad democrática- de que se produjesen muertos. Este es un primer concepto.

El segundo concepto es un concepto práctico. No es que vamos a olvidarnos por un momento de mis ideas y de mis convicciones éticas y vamos a las prácticas [cursivas nuestras]. Era un absurdo, una nimiedad, una estupidez. El decir: para resolver esta presión tengo que sacar esto [policía y fuerzas armadas] simplemente a la calle, era ser suicida o ser tonto. Por lo tanto, contra lo que podría pensarse desde afuera, es verdad: el discurso ético fue un factor muy importante. Pero si no lo hubiera tenido, si hubiera prescindido del discurso ético, me hubiera ido igual. Porque estaba convencido de que quienes me llevaron a donde llegué el 2005, en la crisis de junio, lo que querían eran 60 muertos [destacado nuestro]. Cobraron en la factura, no solamente Evo Morales, Felipe Quispe, Roberto de la Cruz, el radicalismo de izquierda, sino [también] los partidos políticos del propio Sánchez de Lozada, que encontraron un desastre tan grande... Y aparecí de las cenizas, cuando había muchos que habían esperado ser Presidente -y que les correspondía la sucesión constitucional-; que estaban ilusionados con la posibilidad que yo me fuera con Sánchez de Lozada y... ocuparan la presidencia. Entonces era evidente que yo estaba sometido a una trampa. Yo creo que está más que probado. Al principio parecía una paranoia mía. Claro, todo aquel que se va de su gobierno y renuncia, acusa a un tercero de las razones de su renuncia. Pero creo que hoy día hay una conciencia generalizada de que yo fui sometido a una conspiración que tenía como objetivo echarme del poder.

La herramienta más importante, que era la cuestión militar, estaba enfrentada a la posibilidad de repetir un escenario de sangre, con un riesgo adicional: los militares estaban escaldados por el hecho de que -eso es lo que se les dijo-... se les iba a abrir un juicio por las muertes de octubre. Entonces, ¿cuál sería la razón para que militares que cumplen las órdenes de políticos luego son enjuiciados como responsables de crímenes o de violación de derechos y garantías ciudadanas, de las que ellos no son promotores? El Presidente da una instrucción: la constitución establece que es obligación de las fuerzas armadas, en caso de conmoción grave, el salir a imponer el orden y después ellos son... El riesgo adicional era que el ejército se viniera y dijera: lo siento Presidente, pero nosotros somos militares. Eso ocurrió en el último día de gobierno del Presidente Sánchez de Lozada, el jueves o el viernes...Ya las fuerzas armadas no respondieron las órdenes del Presidente porque obviamente el gobierno se estaba cayendo; entonces esto es una suma de elementos...de carácter ético como de carácter práctico". 


\section{Las relaciones con Chile: la política del gas por mar}

"Me doy cuenta perfectamente... que la lectura sea la que no es, porque la estrategia tiene una cierta complejidad... solamente puede ser entendida si uno mira desde dentro lo que pasó. Hay dos cosas que a mí me molestan. La primera me molesta más que la segunda, no solo de mi gobierno, sino del conjunto de los presidentes bolivianos: que se señale que cuando los presidentes bolivianos están en crisis o están a punto de caer sacan la bandera del mar para salvarse. Esa es una generalización que no vale para mi gobierno, y que en general no vale. ¿Qué necesidad tenía un Presidente que en enero de 2004, cuando se genera el conflicto con el Presidente Lagos, tenía el $82 \%$ de respaldo, de usar el mar para salvar su pellejo político? En junio de 2005 se me ocurre hacer una gran alocución marítima: uno puede decir, bueno, trataron de disfrazar o de distraer el interés nacional. No es verdad, ni en mi caso, diría yo, [ni] en la mayor parte de los Presidentes que llevaron adelante realmente políticas de estado en función del tema marítimo, en su relación bilateral con Chile. Esa es una primera aclaración.

Vamos a la segunda. Cuando se produce la crisis de octubre yo me doy cuenta -y eso hay que entenderlo antes del gobierno de Evo Morales- [que] Evo Morales ha estirado de tal manera la relación con Chile por razones que ningún otro Presidente boliviano podría. Es muy importante de saber: ningún Presidente boliviano hubiese gozado de la benevolencia del pueblo boliviano, manteniendo los argumentos si está de acuerdo o no, para ir tan lejos como puede ir [en] su relación con Lagos y con Bachelet. El año 2003 casi era imposible pensar que las relaciones bilaterales de comercio normal podrían llevarse adelante con cierta regularidad. Yo tenía miedo de que comenzaran a cuestionar las exportaciones minerales, porque, además, Evo Morales planteó que no se le compraba nada a Chile: un boicot total. Un hombre con un poder de convocatoria, en ese momento muy grande, un hombre muy poderoso, capaz de echar-bloquear a un gobierno, de desestabilizar un gobierno, de hecho contribuyó a hacer[lo] el año 2005. Entonces lo que yo tenía que tratar era, primero, mantener lo que en ese momento eran relaciones fluidas en todos los temas vinculados al intercambio ChileBolivia, salvo la cuestión marítima [y] la cuestión [del] Silala.

Silala la dejamos congelada, no avanzamos en ninguna dirección, salvo una declaración del Canciller Siles que le produjo dos interpelaciones y dos censuras; una declaración -a propósito- censurada [y]que no viene al caso.

En el tema del mar yo le dije al presidente Lagos claramente: tenemos que reformularlo todo. La propuesta que usted hace -que me parece muy interesante- es simplemente inviable, ya no puede [ser] considerada... sea buena o mala. Entonces plantea la necesidad de reposicionar; y eso tiene que ver con una convicción mía: yo no estuve de acuerdo con la lógica de los gobiernos anteriores, sobre todo con el gobierno del Presidente Sánchez de Lozada... Sánchez

Número de página no utilizable para citas 
de Lozada, muy en el espíritu de su lógica pragmática, pensaba que era el acercamiento económico y comercial el que nos iba a ir aproximando a una solución al tema marítimo: y en esa dirección bajó muy significativamente la temperatura de la reivindicación marítima. A mí me pareció un error; los principios que Bolivia defiende deben ser principios firmes, permanentes y sostenidos porque son política de estado, compartida o no compartida. Esa es mi postura. Entonces mantener que hubiera tenido [relación] la crisis de octubre con la idea de la soberanía [era] para mí el corazón (y siguen siendo el corazón) de la lógica del Estado boliviano en la que teníamos que ir. Y se lo dije al Presidente Lagos, y así lo expresé públicamente.

No nos engañemos; si la palabra soberanía no es parte de la negociación, tiene solución. Chile ha creído y sigue creyendo que hay que suavizar el tema... Como en Chile la palabra soberanía no funciona porque el pueblo chileno no aceptaría esto... hay que tratar de encontrar una salida en esa dirección desde otra vía. Nos olvidamos, por un momento, de eso. Ahora, mi preocupación práctica: Bolivia tenía la potencialidad de exportar entre 10 y 15 mil millones de dólares en el curso de 15 años. Estoy hablando de cifras que hoy día podrían ser de 40 mil. Estoy hablando del año 2003, no del 2008... (eso lo multiplicas por dos). Y que la cantidad de gas que nosotros tenemos permitía -en [el] conjunto de sus requerimientos- industrialización, consumo interno, exportación y transformación; y que eso pasaba (y lo sigo pensando), por California fundamentalmente... Un mercado [en el] que teníamos que competir, porque estaban los australianos, los indonesios, etc., y los propios peruanos. En tanto, el tiempo era oro. Como el tiempo era oro, yo estaba convencido de que si Chile y Bolivia hubieran tenido relaciones fluidas, era obvio (no tenía que pensar dos segundos [en ello]) que la propuesta chilena era la propuesta adecuada. Si estás a 300 kilómetros de distancia con un puerto más próximo, con tu punto de gas aquí y tu puerto aquí, tienes que poner tu punto de transformación aquí; obvio. Pero como era evidente que era imposible en el período [en] que fui Presidente hacer eso con Chile, yo tenía necesariamente que hacer dos cosas. Primero, el precio: convencer a Pacific, que era el consorcio trasnacional de todas las empresas que exportan el gas, de que había un costo adicional que tenían que pagar si querían realmente exportar gas... Dos: convencer a Perú de que esta opción era una opción viable y complementaria, y no competitiva. Es decir, que gas boliviano y gas peruano eran insuficientes para la demanda potencial. Y tres: hacer un nexo con México; para que México ponga el puerto de transformación, porque Estados Unidos, por razones medioambientales, no permite las plantas de transformación en territorio de California. Eso lo tenía que hacer en un plazo breve. $\mathrm{Y}$ esa fue mi gran tarea; o la tarea que tuve que encarar.

En ese sentido pensé, además, que si lográbamos un acuerdo con el Perú, construíamos una planta de transformación en Ilo, Chile por primera vez en la historia se hubiera dado cuenta de algo: que Chile tiene razón. Es obvio que Bolivia y Perú no se iban a poner de acuerdo en nada. Entonces mi lógica [era] -y ahí el tema central: si Chile ve que Bolivia y Perú hacen un proyecto común de carácter energético- construir una planta de transformación en Ilo [y] 
exportan el gas, Chile sabrá que si quiere negociar el gas, lo tendrá que hacer con Bolivia y Perú; y podremos hacer una negociación en la lógica que planteaba: una soberanía que era simplemente una formalidad, es decir un acuerdo entre los tres países, para que al día siguiente de la soberanía entregada a Bolivia (esto ya estaba en el Protocolo Complementario de 1929) íbamos a hacer una soberanía compartida, eliminación de fronteras, desarrollo común, etc. Que ese puerto, una vez boliviano, estuviera en condiciones de ser, en realidad, foco de desarrollo tri-nacional. En ese sentido, la propuesta peruana (que, era obvio, tuvo como objeto bloquear el acuerdo Pinochet-Banzer)...tiene una lógica del siglo XXI interesante. Ese fue el concepto básico esencial. En ningún momento se me paso por la cabeza si Chile me iba a dar medio milímetro de mar o no. Nunca; jamás lo plantee así.

Ahora, posiblemente la pregunta [número 4 del referéndum de 2004] estuvo mal planteada ${ }^{4}$.

En el momento en que se hizo, la gente quería decir: no vamos a hacer ningún tipo de negociación, nunca, con ningún puerto de Chile; ni ningún tipo de acuerdo con Chile... de ninguna naturaleza. También hay que analizar que yo suavice, girando un poco la pregunta... Mi equivocación fue colocar [en ella] el nombre de mi gobierno: ‘¿Está usted de acuerdo con la política de Carlos Mesa?' Es un error, porque posibilita la interpretación vinculante del referéndum [y] porque el gobierno puede ser mal visto. Era el gobierno de Carlos Mesa, no el gobierno de Evo Morales. Pero quiero que se entienda con claridad: esta fue la lógica con que yo hice la pregunta 4.

La primera pregunta que nosotros nos hicimos, cuando... la pregunta tres [del plebiscito de 2004] planteamos la refundación de YPFB $^{5}$ es ¿cómo vamos a financiar YPFB? Y nuestra gran duda era si podíamos manejar las acciones o comprar las acciones (que fueron las que dieron lugar al "bono sol")... en manos de las AFP; acciones que el Presidente Sánchez de Lozada garantizó en un núcleo cerrado, en un fideicomiso, para que nadie las pudiera tocar. Claro, a mí no se me pasó por la cabeza -porque tengo una mentalidad democrática, legalconstitucionalista- que es cuestión de agarrar un decreto y confiscarle a media humanidad... [y] todo lo que Sánchez de Lozada dejo en fideicomiso (bueno o malo, eso es otro tema). Pero no se utilizó ese dinero para el fortalecimiento de los hidrocarburos. Entonces estábamos en el debate de cómo financiábamos. Nosotros considerábamos que YPFB necesitaba entre 1000 y 1200 millones de dólares para arrancar. Ahora, el gobierno cuatro años después, o tres en realidad, después de la nacionalización, se ha abierto un espacio para el uso de las reservas del Banco Central para alimentar YPFB. Hay una polémica sobre eso, pero, en todo caso, mi impresión es que eso llega tarde:... ese impulso debió haber sido simultáneo; es decir, nacionalizó entre comillas, porque no creo que se nacionalizó nada. Además, por si fuera poco

4 Mesa se refiere al plebiscito, patrocinado por su gobierno, llamado "primer referéndum de los hidrocarburos", escenificado el 18 de julio de 2004. La ciudadanía fue convocada a pronunciarse sobre cinco preguntas tocantes a la estrategia nacional que se seguiría de allí en más en relación a los hidrocarburos, incluida su nacionalización y estatificación. La cuarta consulta de los comicios planteaba un claro dilema utilitario: ¿Está usted de acuerdo con la política del Presidente Carlos Mesa para utilizar el gas como un recurso estratégico para recuperar una salida útily soberana al Océano Pacifico?

5 Yacimientos Petrolíferos Fiscales Bolivianos. 
todo lo mal que han hecho, en el curso de dos años hemos pasado de 60 empleados a 1.600 empleados produciendo lo mismo. Porque quienes producen son las empresas trasnacionales, no YPFB".

\section{Si yo fuera Chile: no quedaría sujeto a los vaivenes de la política boliviana}

"Primero creo que hemos vivido el proceso de transformación política del país en un momento de transformación de las matrices energéticas mundiales y hay una cosa que no se ha dicho... Vamos a suponer por un minuto que el Presidente Morales le diga a Chile: quiero vender gas, y quiero hacer un gasoducto. Si yo fuera Chile, no compraría ¿Por qué? Porque voy a estar sujeto a que los bolivianos se pongan de mal humor cada vez que les viene un ataque de patriotismo marítimo y me cortan el gas. Si ya Argentina me lo cortó, prefiero pagar ocho dólares en vez de tres y medio, pero que me dé la garantía de que puedo abastecerme. Yo creo -aún en la hipótesis de que Bolivia le ofreciera gas a Chile- Chile tendría que estar en condiciones tremendamente complicadas para aceptar una condición de esas [características]. Ese es otro factor fundamental. Chile no puede estar sujeto a los vaivenes de la política boliviana [destacado nuestro], que además, en el caso de Chile, no están resueltos. La sensibilidad en el país sigue siendo muy alta, a pesar de que ha bajado la temperatura extraordinariamente cuando yo era Presidente, por razones diversas. Hemos perdido tres años de oro, casi irrecuperables. Estamos enfrentando un segundo gran desafío que es el del litio, el más importante yacimiento de litio del mundo. Nosotros tenemos las reservas más importantes del mundo. Estamos en la gran pregunta: ¿Si la tecnología logra que el hidrógeno sea un mecanismo?, un elemento que pueda ser alimento de baterías, las baterías de litio están muertas para alimentación de vehículos. La tecnología te dice que en un plazo relativamente corto eso puede ocurrir: baterías con hidrógeno. No es que el litio desaparecerá como factor para muchas cosas; pero por una razón básica de precio y de consumo, el litio está en desventaja con el hidrógeno. Eso no está claro todavía; no se ha demostrado que el hidrógeno sea el sustituto".

\section{Sobre la nueva postura chilena a partir de 2005: "ninguna molécula de gas de mis vecinos"}

"Por supuesto... el tema de la molécula es pura retórica, que además... estaba vinculada a una circunstancia: si yo estaba bajo presión absoluta de un tipo que me podía poner un bloqueo en las calles y que me amenazó con un juicio de responsabilidades... bueno OK ni una molécula 
de gas por Chile, sabiendo obviamente que Kichner les iba a dar todas las moléculas que ustedes necesitaran. Esa es una circunstancia política... la frase es demasiado redonda y esas son las frases que te consagran o que te condenan. Lamentablemente me condenó. La hice en un discurso vinculado... [con] que yo al día siguiente tenía que firmar el documento de ampliación de venta de gas a la Argentina y no tenía otro remedio; sino tenía en la calle a medio...y mi debilidad política.

Tú me preguntaste si volvería a hacer lo mismo, renunciar en circunstancias así: sí. Pero llegar donde llegue... ¿Tuve todo el poder en mi país? No... lamentablemente. (El Departamento de) Santa Cruz entendió que el enemigo era yo; Santa Cruz no entendió que el enemigo era Evo Morales. Y en eso Santa Cruz está pagando una factura bien pagada, por hacerme una vida a cuadros, cuando debió haber respaldado mis propuestas genuinas de transformación hacia las autonomías que les hice. Yo que fui el primer Presidente que hizo una propuesta autonómica desde el gobierno; pero bueno... la miopía de la política boliviana dio a entender que estábamos en un vértice de la historia. Es un vértice irreversible, que el Presidente que me sucedía a mi iba a ser indígena. La única diferencia es si yo previamente hubiera podido llevar adelante la agenda de una asamblea constituyente y los referendos autonómicos, [para] que cuando llegase ese Presidente indígena tuviera un marco nuevo de transformaciones. Nunca lo entendió la elite conservadora del país... No estaríamos viviendo esta locura".

\section{Portales y Santa Cruz}

"Es un país que tiene demasiadas complejidades. Yo siempre he dicho que... hay que mirar la historia desde una perspectiva inversa a la que se [la] mira habitualmente. El que Bolivia exista como nación es un gran éxito histórico porque todos los elementos de su constitución llevaron a la conclusión de que es un país sin viabilidad en el tiempo. Estamos acercándonos a los 200 años. Por su situación geográfica, por nuestra constitución étnica, por el quiebre objetivo de dos cordilleras que nos separaban, una del Pacífico y la otra del Amazonas. Por la constitución de los equilibrios de poder que en un sentido han sido contradichos y que tuvimos que enfrentar. Esa es la razón por la que yo siempre he pensado que el hombre más lúcido que tuvimos fue Andrés Santa Cruz. Y que, en efecto, el debate histórico que definió nuestro futuro fue el debate Portales/Santa Cruz. La política portaliana, frontal a la política crucista, definió el destino de Bolivia, de Perú y de Chile.

Porque en el caso, y esa es una de las cosas complejas para los peruanos, que si haces una lectura de la historiográfica peruana, para un peruano es extremadamente difícil aceptar que la geopolítica de estado (en la más grande visión de estado), venga de algo que es excéntrico a Lima; y que además, de algún modo, ha sido arrebatado a Lima. Porque -en la lógica histórica del Perú- los peruanos tienen un dicho: Bolivia debió ser siempre parte del Perú, y la creación

Número de página no utilizable para citas 
de Bolivia es una creación de artificio de Bolívar. Eso impide a los peruanos darle el crédito que Santa Cruz merece.

Si tú analizas, en América Latina, cuando se habla de próceres, jamás se incluye a Santa Cruz (salvo los especialistas): O’Higgins, San Martín, Bolívar... Santa Cruz nunca aparece. Y los bolivianos tienen un gran problema con Santa Cruz. Y si... miras a Bolivia desde Sucre, peor todavía. Porque Santa Cruz es el paradigma de la visión paceña que debilitó el poder de Sucre. Ese es el otro gran punto, porque Sucre nunca pudo prosperar como capital. Qué sentido tenía colocar la capital de un país en el medio de la nada cuando los grandes ejes de decisión de Bolivia estaban en el Pacífico. La Paz era, por obvio peso gravitacional, el punto de referencia para su vinculación con Chile y con Perú, porque todavía en el siglo XIX Brasil no jugaba el papel que comenzó a jugar a partir de la goma, a partir de 1850/1860. Entonces, este es un poco el tema de fondo; estos problemas, más una población indígena a la que el país le dio la espalda, a la que la oligarquía no entendió. La oligarquía boliviana no podía funcionar como la chilena o la argentina, porque Chile no tenía que estar en el corazón del mundo aymará. Y como puedes tú prescindir del mundo aymará cuando tu ciudad más importante es el corazón del mundo aymará. Y pretendes tú, montado en el tributo indígena, negar lo indígena para construir el Estado europeo... era imposible. Entonces tienes ahí un conjunto de temas que explican la problemática. Yo creo que Bolivia ha demostrado una fortaleza, una capacidad. Yo soy un gran admirador de las grandes figuras bolivianas que han salvado a este país del desastre".

\section{Mapa del luto de Bolivia}

"Otro elemento que fue parte de la discusión, y que es uno de los mitos bolivianos, [es] el famoso mapa de luto. Otra más famosa mentira flagrante de que hemos perdido más de la mitad del territorio. La línea que divide el Acre es una línea imaginaria escrita en un mapa. Es exactamente así: un triángulo. No es verdad que -se supone- que va hasta aquí [traza con la mano un triángulo imaginario] y ahora hemos perdido este pedazo [indica con el índice un ángulo] del triángulo. ¿Cuándo hubo un boliviano en esta punta? ¿Cuándo hubo un peruano o un brasileño en medio de la selva amazónica? A quién le interesaba un pepino frito que hubiera un boliviano o un brasileño. Les interesó cuando empezó la goma. Esa línea imaginaria no puede ser real si no tienes una presencia administrativa, judicial, poblacional. Por lo tanto, la pérdida del Acre, medida por Bolivia en 250.000 kilómetros cuadrados, es un disparate. Perdimos el puerto más importante, que fue Puerto Alonso. ¿Qué significa realmente eso? En kilómetros cuadrados ¿cuánto ha perdido realmente Bolivia? Yo diría que entre 25.000 y 30.000 kilómetros cuadrados; es muy diferente de 250.000. En el Chaco quién puede tener un sentido común y decir que Bolivia llegaba (esa es la propuesta, la pretensión boliviana) al vértice del río

Número de página no utilizable para citas 
Paraguay y del río Pilcomayo, es decir a Asunción. Los bolivianos pretendían que el territorio boliviano llegaba literalmente a la primera calle de Asunción. Y los paraguayos pretendían que su territorio llegaba al río Parapeti que está a 200 kilómetros de la actual frontera: de la que perdimos en la guerra. Entonces, en el triángulo del Chaco hemos perdido 220.000 kilómetros cuadrados: disparate pues. ¿Aspiraciones máximas? No solo son aspiraciones máximas: son ilusiones. Con Argentina tres cuartos de lo mismo.

En el caso de Chile, ahí hay una delimitación, por una razón económica obvia. ¿No es verdad? Porque ahí sí había recursos que explotamos. Cuando llega la Guerra del Pacífico, hay dos contradicciones importantes. Uno: tenemos Caracoles, tenemos las salitreras y tenemos Antofagasta. Los dos elementos importantes que tuvo Bolivia previo a la Guerra del Pacífico, mirándola en una estrategia económica, fueron Santa Cruz que establece Lamar [Cobija] como puerto franco y no funciona, porque Cobija no funciona, porque el puerto natural de Bolivia es Arica, punto. Y la segunda estrategia es la creación de Antofagasta, que hace (el Presidente Mariano) Melgarejo, porque se da cuenta que si no tienes una ciudad significativa no vas a poder tener presencia... Si tú desde Santiago de Chile tardas en llegar cuatro días y desde La Paz tardas tres semanas y media, entonces no te tengo que decir quién se va a instalar en Antofagasta. Porque los intereses ingleses valen por igual, sea chileno o boliviano. Pero es obvio que un obrero chileno va a tener más posibilidades de llegar a trabajar ahí que un boliviano, que quizás ni se va a enterar de que esa posibilidad existe. Chile tenía problema del agro también. Eso facilitó la emigración hacia el norte. Exactamente: el 80\% de la población en territorio boliviano es chilena. Por lo tanto, cuando llegan el 14 de febrero las fragatas chilenas, es obvio que se levanta la bandera chilena con gran entusiasmo, que hay intereses ingleses, etc., etc. Ahora bien, ese espacio geográfico, a diferencia de lo que pasaba en el Acre, a diferencia de lo que pasó en el Chaco, [y] en el norte de Argentina, era un espacio económico con objetivos económicos; y objetivos tangibles que rendían dividendos.

La cualidad marítima, la vinculación con la cuenca del Pacífico, no pasó con ninguna de las otras perdidas. Sí se puede cuantificar. Sí puedes discutir el grado o medio grado; podemos decir si son 120.000 o 100.000 [kilómetros cuadrados]. Pero que estamos cerca, ahí no nos equivocamos. Es el único punto, por las razones anotadas, [en] que no hay donde perderse: que es lo que realmente se nos arrebató en términos de territorio. Todos los demás son literatura. Está bien: si a un niño boliviano tú lo educas con la teoría de que ha perdido un millón y fracción de kilómetros cuadrados, hay dos tesis que sustentar. Uno: todos nuestros vecinos eran unos ladrones; dos: los bolivianos eran muy cojudos e imbéciles”.

\section{Construyendo una soberanía trilateral}


"Evidentemente gas por mar funciona mucho mejor que otra cosa, pero es lo último que se me pasó por la cabeza [en su gobierno]. Precisamente porque algo conozco de historia; y sé que cualquier cosa le puedes plantear a Chile, menos un chantaje. Además vas tú a chantajear a Chile. Está bien que Brasil chantajee a Chile, pero Bolivia está medio difícil que chantajee a Chile. Nuestra diferencia, en todos los ámbitos, es tan gigantesca que no estamos en condiciones de hacer eso. Y una de las grandes ilusiones, es, sin duda (si la hubiéramos manejado inteligentemente), si yo lograba en el curso de tres años cerrar el paquete perúboliviano de gas... creo que nuestra relación con Chile hubiera tenido un giro distinto. Chile nos hubiera mirado de otra manera. Chile siempre ha partido de esa hipótesis, que hasta ahora lamentablemente es correcta: Bolivia y Chile no se ponen de acuerdo. Bolivia y Perú no se ponen de acuerdo jamás; y eso me garantiza a mí que yo puedo ser el árbitro de esta política exterior. Otra cosa que me parece inaceptable de Chile es la bilateralidad, ante la obvia trilateralidad, para decir lo menos... Cómo es posible... que no nos podamos reunir tres presidentes, como los que están ahora [2009]. Eso es absurdo. Y eso es una condición sine qua non de Chile. En este momento no: es una locura. Pero suponte que hubiera tres presidentes razonables ¿Por qué no podrían sentarse a discutir? ¿Qué perderían? Si pueden hacerlo israelíes y palestinos por qué no lo van a hacer chilenos, peruanos y bolivianos. Además ¿por qué no hay consuelo juntos? Es decir, aquí el punto es: no hay visión; porque pareciera que el tratado [1929] dijera: ojo tiene que ser en este orden, no tiene que ser... Tú puedes formalmente ir donde se te dé la gana llegar; y después formalmente cumples el tratado. ¿Por qué no pudiéramos chilenos, bolivianos y peruanos construir juntos una propuesta? Esto es algo que no entra en mi cabeza y que increíblemente nunca ha sido una hipótesis planteada por nadie. Damos por obvio que el tratado obliga ...Sí, el tratado es un punto de llegada, pero tú puedes construir ese punto de llegada con un pre-acuerdo que después formalmente... Ya que hemos llegado a un acuerdo los tres, Chile le manda una carta a Perú; Perú dice sí. Ahora bien, dirás: porque iríamos los chilenos a una lógica de esa naturaleza si nuestra línea inalterable de bilateralidad funciona. En eso no te digo nada, pero la lógica del Estado chileno ha funcionado. Y como digo, es mucho más complicado para Bolivia... Pero si tú te das cuenta Bolivia ensaya opciones; y finalmente llegan a la opción que para mí es la opción (siempre y cuando no pasen 20 años). Porque cuando Arica sea un centro urbano que toque la frontera con Perú, te quiero ver. El crecimiento de la ciudad de Arica puede acabar inviabilizando la única solución que a mí me parece posible. En todo caso, el año 1975 -ya han pasado treinta y largos años de ello- se cierra el paquete, es decir se llega al momento más cercano, pero además ese es el referente que yo creo que es el más inteligente. Tanto de parte de Chile como de Bolivia; es decir, esa es la línea de negociación. Tú podrás estar más cerca o más lejos de ir a un enclave: eso no tiene sentido. Que el enclave pudiera ser complementario, a mí me sorprendería (siempre planteando soberanía). El problema es que Chile, y lo entiendo, te dice: momentito, ustedes lo plantean en la lógica de la soberanía, nosotros lo planteamos en un punto más extremo. Lo que hizo el presidente Lagos; cómo compatibilizar esto -insisto- [con] la soberanía, es un trauma histórico de Bolivia. 
Sigo pensando: ... tienes que ser un puente. El puente: tú le vas a dar 48 horas de soberanía [a Bolivia]. La bandera boliviana se iza: somos soberanos. Y luego decimos: somos soberanos y queremos compartirla, y queremos a partir de esta soberanía construir un polo trilateral de desarrollo, donde no hay fronteras, donde no hay nacionalidad, donde no hay nada, donde este puerto es tan boliviano como parte de una estructura de combinación de desarrollo. Este es un poco mi sentido. Creo que plantear una soberanía inflexible es absurdo... Entonces creo que tienes que construir la soberanía y la pos-soberanía sobre la base de que Bolivia va a ceder elementos de esa soberanía, e inmediatamente se la conceda a Chile. Esto significa un acuerdo. Hay un estudio completo que dice: tendrás tu soberanía, izaras tu bandera, y formalmente mantendrás soberanía; pero esa soberanía tendrá los ingredientes de participación soberana de Chile... pero en esto. Esta es la lógica en que yo creo que hay que manejarse... El año 2003, ¿tú ibas a pensar por ventura que el sucesor de Carlos Mesa (el Presidente Evo Morales) iba a invitar al Presidente Lagos a su asunción? No, ¿verdad? Por lo tanto el tiempo corre más rápido de lo que uno cree, el mundo funciona a una velocidad mucho mayor de lo que uno presupone. Yo no soy tan pesimista. (La demanda marítima entre Perú y Chile) La Haya llegará; definirá cualquier cosa que defina ${ }^{6}$. Terminado lo cual, si Bolivia tuviera acceso al mar, no vamos a aceptar la lógica peruana de que nos encierren en un triángulo... Eso es un disparate. Tenemos que renegociarlo aun en una hipótesis peor: de que Perú gane, porque para nosotros esa es la hipótesis peor".

6 Con fecha 27 de enero de 2014, se dio a conocer la sentencia de la Corte Internacional de Justicia. 